\title{
Prevalence, Correlates, and Outcomes of Multimorbidity Among Patients Attending Primary Care in Odisha, India
}

\author{
Sanghamitra Pati, MBBS, MD, \\ $M P H^{1}$ \\ Subbashisa Swain, MPH \\ Mobammad Akbtar Hussain, \\ MBBS, $M D^{2}$ \\ Sbridbar Kadam, MBBS, MD, \\ $M P H^{1}$ \\ Chris Salisbury, $M B, C b B($ Bristol), \\ $M S c$ (Lond), DRCOG, FRCGP, $M D^{3}$ \\ 'Public Health Foundation of India, \\ Indian Institute of Public Health, Bhu- \\ baneswar, Odisha, India \\ ${ }^{2}$ Division of Epidemiology and Biostatistics, \\ School of Public Health, The University of \\ Queensland, Brisbane, Australia \\ ${ }^{3}$ Centre for Academic Primary Care, \\ School of Social and Community Medi- \\ cine, University of Bristol, Bristol, United \\ Kingdom
}

\section{Shl MORE ONLINE www.annfammed.org}

Conflicts of interest: authors report none.

\section{CORRESPONDING AUTHOR}

Sanghamitra Pati, MBBS, MD, MPH Indian Institute of Public Health-Bhubaneswar Public Health Foundation of India 2nd and 3rd Floor, JSS Software

Technology Park

E1/1, Infocity Road, Patia,

Bhubaneswar, Odisha, India

sanghamitra.pati@iiphb.org

\begin{abstract}
PURPOSE Little information is available on multimorbidity in primary care in India. Because primary care is the first contact of health care for most of the population and important for coordinating chronic care, we wanted to examine the prevalence and correlates of multimorbidity in India and its association with health care utilization.
\end{abstract}

METHODS Using a structured multimorbidity assessment protocol, we conducted a cross-sectional study, collecting information on 22 self-reported chronic conditions in a representative sample of 1,649 adult primary care patients in Odisha, India.

RESULTS The overall age- and sex-adjusted prevalence of multimorbidity was $28.3 \%(95 \% \mathrm{Cl}, 24.3-28.6)$ ranging from $5.8 \%$ in patients aged 18 to 29 years to $45 \%$ in those aged older than 70 years. Older age, female sex, higher education, and high income were associated with significantly higher odds of multimorbidity. After adjusting for age, sex, socioeconomic status (SES), education, and ethnicity, the addition of each chronic condition, as well as consultation at private hospitals, was associated with significant increase in the number of medicines intake per person per day. Increasing age and higher education status significantly raised the number of hospital visits per person per year for patients with multiple chronic conditions.

CONCLUSION Our findings of higher prevalence of multimorbidity and hospitalizations in higher SES individuals contrast with findings in Western countries, where lower SES is associated with a greater morbidity burden.

Ann Fam Med 2015;13:446-450. doi: 10.1370/afm.1843.

\section{INTRODUCTION}

M ultimorbidity, the co-occurrence of 2 or more (chronic) conditions within the same individual, is linked to higher health care use, higher expenditure, and impaired quality of life. ${ }^{1-3}$ In the developing countries, little information on multimorbidity is available and is based on secondary data and limited to a only a few chronic conditions and geriatric groups. ${ }^{4-6}$ With our previous study, for which data were based on the World Health Organization (WHO) Study on Global Aging and Adult Health (SAGE), we reported a $8.9 \%$ prevalence of multimorbidity in Indian adults. ${ }^{7}$ Our systematic review on multimorbidity in South Asia found a lack of uniformity in the definition and assessment of multimorbidity, and no information from primary care in India. ${ }^{8}$ Given the importance of primary care for delivering coordinated chronic care, and that primary care being the first contact for most populations in India, it is important that we understand the magnitude of multimorbidity in these settings. We therefore undertook this first study to estimate the prevalence of multimorbidity among adult patients attending public and private primary care and to examine the socioeconomic correlates and health care use. The study was exploratory; we restricted it to Odisha, an Indian state (approximate population share of $4 \%$ of the total population of India) with average health indicators and comparable health system characteristics. ${ }^{9}$ 


\section{Table 1. Multimorbidity Prevalence and Its Association With Different Sociodemographic Characteristics:} Results From Univariate and Multivariate Analyses $(\mathrm{N}=1,649)$

\begin{tabular}{|c|c|c|c|c|}
\hline Characteristics & $\begin{array}{c}\text { No. } \\
\text { (Weighted \%) }\end{array}$ & $\begin{array}{l}\text { Percentage With } \\
\text { Multimorbidity } \\
\text { Weighted \% } \\
(95 \% \text { Cl) }\end{array}$ & $\begin{array}{c}\text { Crude } \\
\text { Odds Ratio } \\
(95 \% \mathrm{Cl})\end{array}$ & $\begin{array}{c}\text { Adjusted } \\
\text { Odds Ratio } \\
(95 \% \mathrm{Cl})\end{array}$ \\
\hline Age-group ${ }^{b}$ & & & [Reference] & [Reference] \\
\hline $18-29$ y & $373(22.6)$ & $5.8(1.99-9.6)$ & & \\
\hline $30-39$ y & $297(18.1)$ & $22.2(15.1-29.4)$ & $4.79(2.73-8.39)$ & $6.10(3.19-11.65)^{c}$ \\
\hline $40-49$ y & $346(20.5)$ & $24.3(17.7-30.9)$ & $6.14(3.58-10.54)$ & $8.49(4.45-16.117)^{c}$ \\
\hline $50-59$ y & $266(16.7)$ & $36.2(27.9-44.5)$ & $11.24(6.54-19.29)$ & $16.41(8.55-31.48)^{c}$ \\
\hline $60-69$ y & $236(14.6)$ & $36.9(28.1-45.8)$ & 11.09 (6.41-19.19) & $16.14(8.38-31.10)^{c}$ \\
\hline$\geq 70 y$ & $131(07.5)$ & $44.4(33.0-55.8)$ & $15.01(8.25-12.30)$ & $22.35(11.15-44.71)^{c}$ \\
\hline \multicolumn{5}{|l|}{$\operatorname{Sex}^{\mathrm{b}}$} \\
\hline Male & $921(55.8)$ & $25.1(22.1-28.0)$ & [Reference] & [Reference] \\
\hline Female & $728(44.2)$ & $32.5(29.0-35.9)$ & $1.37(1.08-1.73)$ & $1.61(1.23-2.12)^{c}$ \\
\hline \multicolumn{5}{|l|}{ Place of living } \\
\hline Rural & $1,493(90.4)$ & $25.5(23.2-27.8)$ & [Reference] & [Reference] \\
\hline Urban & $156(9.6)$ & $28.5(27.8-29.3)$ & $1.36(0.88-2.11)$ & $1.39(0.86-2.27)$ \\
\hline \multicolumn{5}{|l|}{ Ethnicity } \\
\hline Aboriginal & $471(28.0)$ & $27.7(26.3-29.2)$ & [Reference] & [Reference] \\
\hline Nonaboriginal & $1,178(71.4)$ & $28.5(27.6-29.4)$ & $1.68(1.28-2.21)$ & $1.57(1.16-2.13)^{c}$ \\
\hline \multicolumn{5}{|l|}{ Socioeconomic status } \\
\hline Below poverty line & $1,035(61.6)$ & $28.8(27.8-29.7)$ & [Reference] & [Reference] \\
\hline Above poverty line & $601(38.4)$ & $27.5(26.2-28.8)$ & $1.34(1.05-1.70)$ & $1.35(1.03-1.78)^{c}$ \\
\hline \multicolumn{5}{|l|}{ Schooling } \\
\hline No School & $642(38.1)$ & $35.0(33.7-36.3)$ & [Reference] & \\
\hline Primary completed & $514(30.7)$ & $28.3(27.1-29.5)$ & $1.22(0.93-1.61)$ & $1.61(1.17-2.22)^{c}$ \\
\hline Secondary and above & $493(31.1)$ & $20.1(19.6-21.1)$ & $0.68(0.50-0.91)$ & $1.53(1.03-2.25)^{c}$ \\
\hline \multicolumn{5}{|l|}{ Marital status } \\
\hline Currently married & $1,321(79.8)$ & $29.3(28.5-30.1)$ & [Reference] & [Reference] \\
\hline Currently not married & $328(20.2)$ & $24.3(22.0-26.6)$ & $0.74(0.55-1.01)$ & $1.45(0.97-2.15)$ \\
\hline \multicolumn{5}{|l|}{ Facility } \\
\hline Public & $849(61.0)$ & $28.1(27.1-29.1)$ & [Reference] & [Reference] \\
\hline Private & $800(39.0)$ & $28.6(27.5-29.7)$ & $1.35(1.06-1.71)$ & $1.40(1.08-1.81)^{c}$ \\
\hline Total & $1,649(100.0)$ & $28.3(25.9-30.7)$ & & \\
\hline
\end{tabular}

\section{METHODS}

We conducted a cross-sectional study from October 2013 to March 2014 on 1,670 adult patients from 40 primary health care facilities (20 public and 20 private) by using a multistage, stratified random sampling. Participants were interviewed by 4 trained nurses using a structured multimorbidity assessment protocol (MAP). The 22 included health conditions (Supplemental Appendix at http://www.annfammed. org/content/13/5/446/supp1/DC1) were based on an extensive literature search followed by a chart review of the most frequent chronic conditions encountered in primary care. The 9-item Patient Health Questionnaire (PHQ-9) was used for ascertaining depression (a cutoff score of 10 or more was considered to be positive for depression). ${ }^{10,11}$ Additionally, we elicited health care use in terms of number of outpatient visits and inpatient admissions in the last 12 months per person per year and count of medications per person per day. The study was approved by the Institutional Ethics Committee of Public Health Foundation of India, New Delhi.

We defined multimorbidity as having 2 or more chronic conditions. We calculated age- and sexadjusted prevalence across sociodemographic variables and used binary logistic regression analysis to estimate adjusted odds of association of various sociodemographic correlates with multimorbidity. A trend test was performed to investigate whether the probability of having multiple chronic morbid conditions varied across the age-group and by sex. Within multimor- 


\section{Figure 1 . Percentage of population with more than 1 chronic condition, by age and sex.}

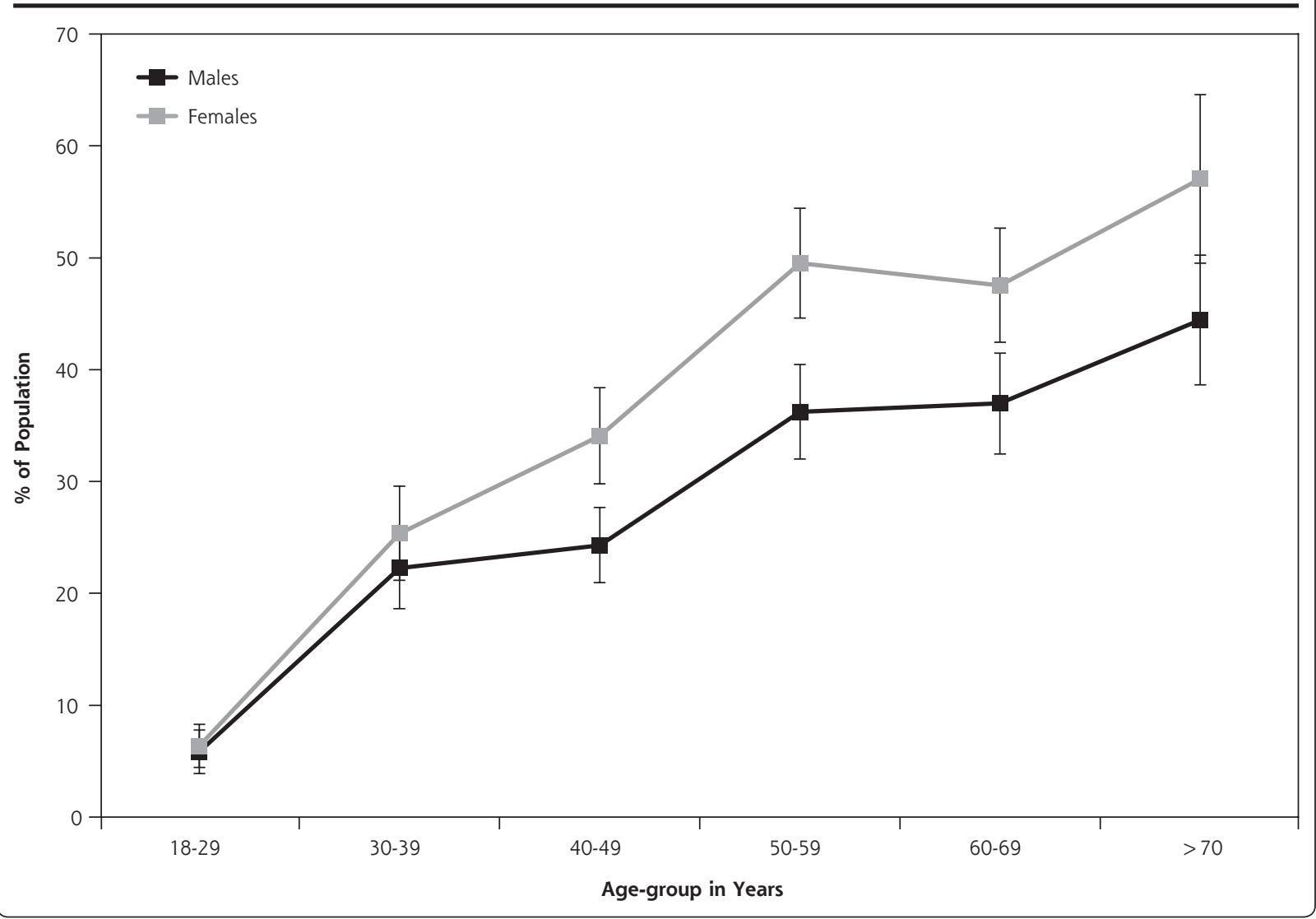

bidity, the associated factors for health care use were explored using negative binomial regression analysis and expressed as incidence rate ratio (IRR).

\section{RESULTS}

Of 1,649 patients interviewed, more than one-half $(54.7 \%)$ had at least 1 chronic condition, and 28.3\% had more than 1 chronic condition (Table 1). The prevalence of multimorbidity ranged from $5.8 \%$ in patients aged 18 to 29 years to $44.4 \%$ in patients aged 70 years and more ( $\chi^{2}$ for trend $=12.12, P<.001$ ) (Figure 1). Patients had higher odds of having multiple morbidities if they were of older age, female, of higher socioeconomic status, and nonaboriginal if they had high levels of education, and if they were visiting private health care facilities (Table 1). The mean number of hospital visits per patient per year was 1.62 (95\% CI, 1.31-1.93) and 2.81 (95\% CI, 2.34-3.28) among patients with single chronic conditions and multimorbidities, respectively. The mean number of medicine used increased from 0.56 (95\% CI, 0.50-0.62) among patients with single chronic conditions to 1.17 (95\% CI, 1.04-1.29) among patients with multimorbidities.
Among patients with multimorbidities, the number of medicines taken was 1.39 times higher among those attending private health care facilities than those visiting public facilities (Table 2). Each additional chromic condition was expected to increase the number of medicines taken by 1.30 times after adjusting for other variables in the model. Increasing age and level of education, however, were significantly associated with higher number of hospital visits (Table 2).

\section{DISCUSSION}

Using a broad nosological spectrum, we found the prevalence of multimorbidity to be $28.3 \%$, similar to that reported for other high- and middle-income countries. ${ }^{12-14}$ This rate is higher than our previous findings, ${ }^{7}$ which could be due to a difference in the number of conditions included to define multimorbidity. ${ }^{15}$ The higher likelihood of multimorbidity among older adults, women, and those with higher income level is congruent with findings from studies from South Asia. ${ }^{4,6}$ The observed inverse correlation between socioeconomic status and multimorbidity, though, contrasts with that of Western countries, but 


\begin{tabular}{|c|c|c|}
\hline Characteristics & $\begin{array}{c}\text { IRR for } \\
\text { Medicines Taken } \\
\text { No. }(95 \% \mathrm{Cl})\end{array}$ & $\begin{array}{l}\text { IRR for Visits } \\
\text { to Hospital } \\
\text { No. }(95 \% \mathrm{Cl})\end{array}$ \\
\hline \multicolumn{3}{|l|}{ Age } \\
\hline $18-29$ y & [Reference] & [Reference] \\
\hline $30-39$ y & $1.17(0.64-2.14)$ & $1.94(0.91-4.12)$ \\
\hline $40-49 y$ & $1.25(0.70-2.23)$ & $2.15(1.07-4.34)^{\mathrm{a}}$ \\
\hline $50-59$ y & $1.20(0.68-2.12)$ & $1.86(1.01-3.77)^{\mathrm{a}}$ \\
\hline $60-69 y$ & $1.13(0.63-2.02)$ & $2.02(1.02-2.99)^{\mathrm{a}}$ \\
\hline$\geq 70 y$ & $1.28(0.69-2.34)$ & $1.85(0.90-3.81)$ \\
\hline \multicolumn{3}{|l|}{ Sex } \\
\hline Male & [Reference] & [Reference] \\
\hline Female & $1.00(0.82-1.21)$ & $1.07(0.77-1.49)$ \\
\hline \multicolumn{3}{|l|}{ Place of living } \\
\hline Rural & [Reference] & [Reference] \\
\hline Urban & $0.83(0.68-1.00)$ & $1.09(0.64-1.88)$ \\
\hline \multicolumn{3}{|l|}{ Ethnicity } \\
\hline Aboriginal & [Reference] & [Reference] \\
\hline Nonaboriginal & $1.21(0.90-1.63)$ & $1.08(0.80-1.46)$ \\
\hline \multicolumn{3}{|l|}{ Schooling } \\
\hline No schooling & [Reference] & [Reference] \\
\hline Primary completed & $0.73(0.59-1.01)$ & $1.43(1.08-1.89)^{\mathrm{a}}$ \\
\hline Secondary and above & $0.89(0.71-1.10)$ & $1.49(1.03-2.24)^{\mathrm{a}}$ \\
\hline \multicolumn{3}{|l|}{ Socioeconomic Status } \\
\hline Below poverty line & [Reference] & [Reference] \\
\hline Above poverty line & $1.13(0.93-1.36)$ & $1.03(0.77-1.36)$ \\
\hline \multicolumn{3}{|l|}{ Marital status } \\
\hline Currently married & [Reference] & [Reference] \\
\hline Currently not married & $1.11(0.84-1.47)$ & $1.17(0.85-1.61)$ \\
\hline \multicolumn{3}{|l|}{ Facility } \\
\hline Public & [Reference] & [Reference] \\
\hline Private & $1.39(1.17-1.66)^{\mathrm{a}}$ & $1.20(0.91-1.58)$ \\
\hline Number of morbidities & $1.30(1.20-1.40)^{\mathrm{a}}$ & $1.05(0.91-1.21)$ \\
\hline \multicolumn{3}{|l|}{ IRR = incidence rate ratio. } \\
\hline \multicolumn{3}{|c|}{$\begin{array}{l}\text { a Significant at } P<.05 \text {, adjusted for age-group, sex, ethnicity, education, } \\
\text { socioeconomic status, marital status, place of living, number of morbidities as } \\
\text { continuous and types of facility. }\end{array}$} \\
\hline
\end{tabular}

it is consistent with previous findings from India. ${ }^{7,16}$ Such a strong correlation of higher SES with increased multimorbidity could be attributed to apparently contrasting socioeconomic patterns of risk factors for noncommunicable diseases in India, as well as in other developing countries, ${ }^{17}$ compared with developed countries. Low health care-seeking behavior and probability of underdiagnosis among low-income populations could be one possible explanation. ${ }^{18}$

As with our previous findings, we observed an increase in the number of medicines taken with the increasing number of chronic conditions. ${ }^{2}$ The significant association between older age and higher education with a higher number of hospital visits could be attributed to increased health literacy among the patients. ${ }^{19}$

Overall, our observations indicate multimorbidity to be a prevalent phenomenon among Indian primary care patients and provide novel epidemiological evidence of its magnitude and impact on health care use for one Indian state. These observations have not previously been explored in such detail. Because of the methodology used, our prevalence estimates, even though from a single province, reflect closely the multimorbidity in Indian primary care. Our finding suggests redesigning the current national health programs that focus on single diseases to address multimorbidity more effectively, with particular attention to primary care strengthening and developing contextualized health care protocols.

To read or post commentaries in response to this article, see it online at http://www.annfammed.org/content/13/5/446.

Key words: multimorbidity; primary health care; India; chronic disease; prevalence; health care utilization

Submitted November 21, 2014; submitted, revised, July 12, 2015; accepted July 21, 2015.

Previous presentation: Presented at WONCA South Asia Conference-2014; August 16-17, 2014; Chennai, India.

Funding support: This work was supported by a Wellcome Trust Capacity Strengthening Strategic Award to the Public Health Foundation of India and a consortium of UK universities.

Disclaimer: The sponsors of the study had no role in study design, data collection, data analysis, data interpretation, or writing of the report. The corresponding author had full access to all the data in the study and had final responsibility for the decision to submit for publication.

Acknowledgments: We sincerely thank the Department of Health and Family Welfare, Government of Odisha, for their valuable support. We are also thankful to Indian Medical Association, Odisha branch, and all medical officers and private practitioners for facilitating data collection. We are grateful to all study participants for providing valuable information and sharing their experiences.

Supplementary materials: Available at http://www.AnnFamMed. org/content/13/5/446/supplDC1/

\section{References}

1. Mercer SW, Smith SM, Wyke S, O'Dowd T, Watt GC. Multimorbidity in primary care: developing the research agenda. Fam Pract. 2009;26(2):79-80.

2. Glynn LG, Valderas JM, Healy $P$, et al. The prevalence of multimorbidity in primary care and its effect on health care utilization and cost. Fam Pract. 2011;28(5):516-523.

3. Payne RA, Abel GA, Guthrie B, Mercer SW. The effect of physical multimorbidity, mental health conditions and socioeconomic deprivation on unplanned admissions to hospital: a retrospective cohort study. CMAJ. 2013;185(5):E221-E228. 
4. Khanam MA, Streatfield PK, Kabir ZN, Qiu C, Cornelius C, Wahlin A. Prevalence and patterns of multimorbidity among elderly people in rural Bangladesh: a cross-sectional study. J Health Popul Nutr. 2011;29(4):406-414.

5. Nimako BA, Baiden F, Sackey SO, Binka F. Multimorbidity of chronic diseases among adult patients presenting to an inner-city clinic in Ghana. Global Health. 2013;9:61.

6. Banjare P, Pradhan J. Socio-economic inequalities in the prevalence of multi-morbidity among the rural elderly in Bargarh District of Odisha (India). PLoS One. 2014;9(6):e97832.

7. Pati S, Agrawal S, Swain $S$, et al. Non communicable disease multimorbidity and associated health care utilization and expenditures in India: cross-sectional study. BMC Health Serv Res. 2014;14(1):451.

8. Pati $S$, Swain $S$, Hussain MA, et al. Prevalence and outcome of multimorbidity in South Asia: a systematic review. BMJ Open (in press).

9. Ministry of Statistics and Program Implementation. Annual Health Survey 2012-13; Odisha. New Delhi: Vital Statistics Division Office of the Registrar General \& Census Commissioner, India; 2012. http://www.censusindia.gov.in/vital_statistics/AHSBulletins/AHS_ Factsheets_2012-13/FACTSHEET-Odisha.pdf.

10. Kochhar PH, Rajadhyaksha SS, Suvarna VR. Translation and validation of brief patient health questionnaire against DSM IV as a tool to diagnose major depressive disorder in Indian patients. J Postgrad Med. 2007;53(2):102-107.

11. Ganguly S, Samanta M, Roy P, Chatterjee S, Kaplan DW, Basu B. Patient health questionnaire- 9 as an effective tool for screening of depression among Indian adolescents. J Adolesc Health. 2013;52(5): 546-551.
12. Salisbury C, Johnson L, Purdy S, Valderas JM, Montgomery AA. Epidemiology and impact of multimorbidity in primary care: a retrospective cohort study. Br J Gen Pract. 2011;61(582):e12-e21.

13. Britt HC, Harrison CM, Miller GC, Knox SA. Prevalence and patterns of multimorbidity in Australia. Med J Aust. 2008;189(2):72-77.

14. Den Van Akker. Buntiux F, Metsemakers J, Roos S, Knottnerus JA. Multimorbidity in general practice: prevalence, incidence and its determinants of co-occuring chronic and recurrent diseases. J Clin Epidemiol. 1998;51(5):367-375.

15. Fortin M, Stewart M, Poitras M-E, Almirall J, Maddocks H. A systematic review of prevalence studies on multimorbidity: toward a more uniform methodology. Ann Fam Med. 2012;10(2):142-151.

16. Barnett K, Mercer SW, Norbury M, Watt G, Wyke S, Guthrie B. Epidemiology of multimorbidity and implications for health care, research, and medical education: a cross-sectional study. Lancet. 2012;380(9836):37-43.

17. Dinsa GD, Goryakin Y, Fumagalli E, Suhrcke M. Obesity and socioeconomic status in developing countries: a systematic review. Obes Rev. 2012;13(11):1067-1079.

18. Sikder SS, Labrique AB, Ullah B, et al. Care-seeking patterns for fatal non-communicable diseases among women of reproductive age in rural northwest Bangladesh. BMC Womens Health. 2012;12(1):23.

19. Hudon C, Fortin M, Poitras M-E, Almirall J. The relationship between literacy and multimorbidity in a primary care setting. BMC Fam Pract. 2012;13(1):33.

\section{Conference on

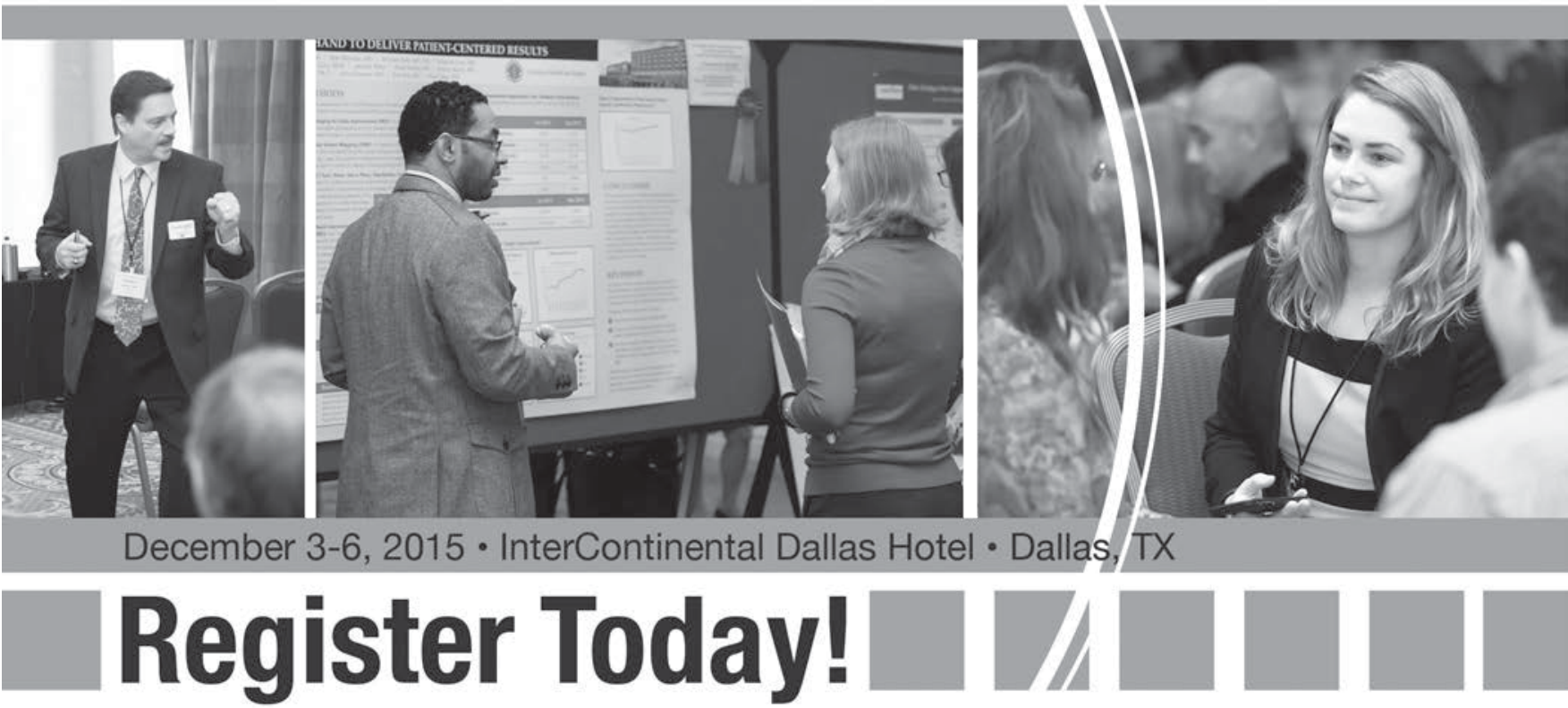

Produced by the Society of Teachers of Family Medicine in collaboration with the American Academy of Family Physicians. 